\title{
Interleukin-8 as a Surrogate Marker in Risk Stratification of Patients with Acute Myeloid Leukemia
}

Mohammed Abdul Wahid Almorish ${ }^{1}$, Waiel Mohmed Abdo Al-Kahiry ${ }^{2 *}$, Maha Abubakr Feissal Rabie ${ }^{3}$ and Enas Ali Mohamed Dammag ${ }^{4}$

${ }^{1}$ Department of Hematology, Faculty of Medicine and Medical Sciences, Sana'a University, Yemen

${ }^{2}$ Department of Hematology Oncology, Faculty of Medicine, Aden University, Yemen

${ }^{3}$ Department of Medical Laboratory Technology, Pharos University, Alexandria, Egypt

${ }^{4}$ Department of Clinical Hematology, Faculty of Medicine, Taiz University, Yemen

\begin{abstract}
Introduction: When molecular and cytogenetic studies are not available, the risk stratification of AML patients will be difficult. This study was conducted to evaluate the prognostic value of IL-8 among AML patients with its relation to outcome.

Methods: This is a cross sectional study; 42 newly diagnosed AML patients ( $<65$ years) were investigated with determination of serum IL-8 by ELISA and followed up for 36 months. In addition, 20 sex and age matched normal volunteers were included as control.

Results: In AML patients, serum IL-8 was ranging from 5 to $200 \mathrm{pg} / \mathrm{mL}$ with a mean of $76.5 \mathrm{pg} / \mathrm{mL}$. It was significantly higher among AML patients when compared to the control $(76.5 \mathrm{vs} 32.3 \mathrm{pg} / \mathrm{mL})$. The mean did not show any significant relationship to patients' sex or the FAB classification of AML $(p>0.05)$. While significant higher mean was observed among poor cytogenetic risk group $(110.4 \mathrm{pg} / \mathrm{mL})$ as well as among died patients $(108.8 \mathrm{pg} / \mathrm{mL})$ and refractory patients $(84.2 \mathrm{pg} / \mathrm{mL})$. In regard to survival, among those with $\mathrm{IL}-8>40 \mathrm{pg} / \mathrm{mL}$, the mean survival time was higher in comparison to AML patients with IL-8 $\leq 40 \mathrm{pg} / \mathrm{mL}$ ( 34.6 months vs 26.3 months).
\end{abstract}

Conclusion: This study concluded that serum IL-8 concentration at presentation of AML patients is high and it could be used as a marker for risk stratification for AML patients.

Keywords: Acute myeloid leukemia; Leukemia; IL-8 Outcome; Prognosis

\section{Introduction}

Acute myeloid leukemia (AML) is a clonal aggressive stem cell disorder characterized by failure of differentiation and overproliferation of stem cell compartment resulting in accumulation of non-functional myeloid cells (myeloblasts) and loss of normal hematopoietic function [1].

In 2016, the World Health Organization (WHO) established an extended classification in hematology which integrated blast morphology, immunophenotype, cytogenetics with molecular studies to establish diagnoses of AML with prognostic relevance. They even extended the number of recurrent genetic abnormalities and added categories for subtypes of AML with gene mutations [2].

The prognosis in AML patients is related to the frequently observed dysfunction in their immune system that hampers the development of an effective response against leukemic blasts $[3,4]$.

Cytokines are released by different types of cells in response to a variety of stimuli such as tissue damage or infection to regulate the immune response and other biologic processes [5]. In patients with AML, cytokines may be produced by the leukemic cells and/or by the immune system cells. The production of such cytokines may play role in the pathogenesis of AML such as blasts proliferation, inhibition of apoptosis and resistance to chemotherapy. It may even play role in determining prognosis in AML patients [6,7].

Interleukin designates any soluble protein or glycoprotein product of leukocytes that regulates the responses of other leukocytes. IL- 8 is a potent, proinflmmatory chemokine that induces chemotaxis of neutrophils across the vascular wall. Studies reported its association with tumor growth, an effect attributed to its angiogenic activity while other studies reported its antitumor effects [8].
In areas with low resources, where molecular studies are not available, the risk stratification of the 2016 classification of AML will be impossible to apply to AML patients. We are in immense need for simple prognostic markers. This study was conducted to test the prognostic value of IL-8 among AML patients with its relation to outcome.

\section{Patients and Methods}

This is a prospective study which included 42 newly diagnosed adult AML patients ( $<65$ years) managed in the Hematology Department of the Medical Research Institute, Alexandria University Main Hospital and Gamal Abdul-Naser Insurance Hospital in Alexandria, Egypt from June 2015 to June 2018. In addition, 20 sex and age matched normal volunteers were included as control.

In this study, AML patients with mixed lineage expression, coexisting secondary malignancy, autoimmune diseases, and traumas were excluded.

Diagnosis of AML was based on the finding of $\geq 20 \%$ blasts in the bone marrow and the flow cytometry was used to characterize the leukemic blasts and exclude mixed lineage leukemia using acute panel

*Corresponding author: Waiel Mohmed Abdo Al-Kahiry, Faculty of Medicine, Aden University, Yemen, 47 (A) Memphis, Camp Chezar, Alexandria, Egypt, Tel: 00201115535969; E-mail: Kahiry13@gmail.com

Received February 13, 2019; Accepted March 18, 2019; Published March 25 , 2019

Citation: Almorish MAW, Al-Kahiry WMA, Rabie MAF, Dammag EAM (2019) Interleukin-8 as a Surrogate Marker in Risk Stratification of Patients with Acute Myeloid Leukemia. J Blood Lymph 9: 240.

Copyright: $\odot 2019$ Almorish MAW, et al. This is an open-access article distributed under the terms of the Creative Commons Attribution License, which permits unrestricted use, distribution, and reproduction in any medium, provided the original author and source are credited. 
of monoclonal antibodies labeled by Fluorescein Isothiocyanate (FITC) (green) or Phycoerythrin (PE) (red). The ELISA sandwich method was followed for determination of serum IL-8 using BioVendor Human Interleukin-8 ELISA (RD194558200R).

Cytogenetic studies were done by Fluorescence in situ Hybridization (FISH) analysis and the patients were classified as favorable, intermediate and poor risk groups based on the cytogenetic findings [9].

Blood samples for IL-8 were taken prior to the start of chemotherapy and patients who presented with infection were managed first prior to sampling to rule out the effect of infection in IL-8 elevation.

The response to treatment was defined according to the 2017 ELN recommendations[10]. Complete remission (CR) was defined by bone marrow blasts $<5 \%$ durable for at least 28 days, absence of blasts with Auer rods, absence of extramedullary disease, absolute neutrophil count $>1.0 \times 10^{9} / \mathrm{L}$, platelet count $>100 \times 10^{9} / \mathrm{L}$, independence of red cell transfusions. Partial remission (PR) was defined by all hematologic criteria of CR, decreased bone marrow blast percentage to $5-25 \%$ and decreased pretreatment bone marrow blast percentage by at least $50 \%$. Refractory disease (RD) was defined as the failure to achieve CR or $\mathrm{PR}$, only includes patients surviving $\geq 7$ days following completion of initial treatment, with evidence of persistent leukemia by blood and/or bone marrow examination.

Data processing was performed by the Statistical Package for Social Sciences (SPSS ver. 24) for Windows which revealed normally distributed (parametric) data. Accordingly, parametric tests were conducted ( $t$ test for two means and one way ANOVA for more than 2 means). Qualitative variables were tested by the Chi-square test. The ROC curve was conducted to estimate the cut off value with the highest sensitivity and the survival analysis was conducted by the Kaplan Meier method. All tests were conducted with the $95 \%$ confidence interval and $p$-values of $\leq 0.05$ were considered statistically significant.

\section{Results}

In this study, higher percentage of acute myeloid leukemia was diagnosed among male patients (59.5\%). The age was ranging from 19 to 64 years and the median age was 48 years (M: F ratio of $1.47: 1)$ (Table 1).

The clinical findings revealed that fatigue and bone pain are the main complaints ( $92.9 \%$ and $76.2 \%$, respectively) followed by bleeding and fever (61.9\% and $52.4 \%$, respectively). The common FAB type was M4 followed by M2, M3 then M5 (Table 2).

Peripheral blood finings among the studied AML patients revealed that the mean hemoglobin concentration was $7.26 \mathrm{~g} / \mathrm{dL}$, the mean total leukocytic count was $36.39 \times 10^{9} / \mathrm{L}$ and the mean platelets count was $52.5 \times 10^{9} / \mathrm{L}$. The bone marrow myeloblast was ranging from 22 to $90 \%$. Serum IL-8 was ranging from 5 to $200 \mathrm{pg} / \mathrm{mL}$ with a mean value of 76.5 $\mathrm{pg} / \mathrm{mL}$ (Table 3 ).

\begin{tabular}{|l|l|l|l|l|}
\hline \multirow{2}{*}{ Sex } & Item & AML patients (n=42) & Control (n=20) & p-value \\
\cline { 2 - 4 } & Male & $25(59.5 \%)$ & $12(60.0 \%)$ & 0.971 \\
\cline { 2 - 4 } & Female & $17(40.5 \%)$ & $8(40.0 \%)$ & \\
\hline \multirow{2}{*}{ Age (years) } & Mean \pm s.d & $48.6 \pm 8.1$ & $44.1 \pm 10.5$ & 0.069 \\
\cline { 2 - 4 } & Median (min-max) & $48(19-64)$ & $45(22-64)$ & \\
\cline { 2 - 4 } p-values are statistically insignificant (>0.05) & & \\
\hline
\end{tabular}

Table 1: Sex and age of the studied patients with Acute Myeloid Leukemia and of the control group.

\begin{tabular}{|l|l|l|l|l|l|}
\hline Clinical data & No. & $\%$ & FAB type & No. & $\%$ \\
\hline Fatigue & 39 & 92.9 & AML-M1 & 3 & 7.1 \\
\hline Bone pain & 32 & 76.2 & AML-M2 & 10 & 23.8 \\
\hline Bleeding & 26 & 61.9 & AML-M3 & 8 & 19.0 \\
\hline Fever & 22 & 52.4 & AML-M4 & 12 & 28.6 \\
\hline Hepatomegaly & 15 & 35.7 & AML-M5 & 6 & 14.3 \\
\hline Splenomegaly & 12 & 28.6 & AML-M6 & 2 & 4.8 \\
\hline Lymphadenopathy & 4 & 9.5 & AML -M7 & 1 & 2.4 \\
\hline Percentages were calculated from the total sample size (n=42) &
\end{tabular}

Table 2: Clinical data and FAB classification of the included patients with acute myeloid leukemia.

\begin{tabular}{|l|l|l|l|}
\hline Parameter & Min-Max & Mean \pm s.d. & Median \\
\hline Hemoglobin concentration $(\mathrm{g} / \mathrm{dL})$ & $4.2-13.3$ & $7.26 \pm 2.3$ & 6.8 \\
\hline Total leukocytic count $\left(\times 10^{9} / \mathrm{L}\right)$ & $0.92-258.6$ & $36.39 \pm 48.8$ & 21.25 \\
\hline Platelets count $\left(\times 10^{9} / \mathrm{L}\right)$ & $12.0-136.0$ & $52.6 \pm 32.7$ & 41.0 \\
\hline Blasts $(\%)$ & $22.0-90.0$ & $56.8 \pm 16.8$ & 65.0 \\
\hline IL-8 $(\mathrm{pg} / \mathrm{mL})$ & $5.0-200$ & $76.5 \pm 48.7$ & 73.0 \\
\hline IL: Interleukin & & \\
\hline
\end{tabular}

Table 3: Laboratory parameters in the included patients with Acute Myeloid Leukemia.

The mean serum IL-8 was significantly higher among AML patients $(76.5 \pm 48.7 \mathrm{pg} / \mathrm{mL})$ when compared to the control $(32.3 \pm 8.5 \mathrm{pg} / \mathrm{mL})$ $(\mathrm{F}=16.0, p=0.001)$ (Figure 1).

The follow-up period was 36 months, during which $35.7 \%$ of patients were died and $4.8 \%$ were lost during follow-up. The remainders showed complete remission (16.7\%) by clinical and laboratory findings, partial remission $(31.0 \%)$, and $11.9 \%$ were refractory to treatment (Figure 2).

The mean serum IL-8 did not show any significant relationship to patients' sex or the FAB classification of AML ( $p>0.05)$. While significant higher mean was observed in relation to cytogenetic risk groups and the outcome. In those with favorable risk it was $(54.3 \mathrm{pg} /$ $\mathrm{mL})$, in those with intermediate risk it was $(66.3 \mathrm{pg} / \mathrm{mL})$ while in those with poor risk it was higher $(110.4 \mathrm{pg} / \mathrm{mL})$. Among died patients $(108.8$ $\mathrm{pg} / \mathrm{mL})$ and refractory patients $(84.2 \mathrm{pg} / \mathrm{mL})$, when compared to those with partial remission $(66.2 \mathrm{pg} / \mathrm{mL})$ or complete remission $(21.4 \mathrm{pg} /$ $\mathrm{mL}$ ) (Table 4).

When the studied patients were grouped based on the cytogenetic risk groups, the mean survival time was higher among those with favorable cytogenetic findings (33.7 months) in comparison to those with intermediate or poor cytogenetic findings ( 28.3 months and 24.8 months, respectively) but not found statistically significant $(p=0.195)$ (Figure 3).

Using the ROC curve for IL-8, the cut off value with highest sensitivity was $40 \mathrm{pg} / \mathrm{mL}$. At this cut off value, the survival of patients with AML showed significant variation $(p=0.023)$. Among those with IL- $8>40 \mathrm{pg} / \mathrm{mL}$, the mean survival time was significantly higher in compare to AML patients with IL- $8 \leq 40 \mathrm{pg} / \mathrm{mL}$ (34.6 months vs 26.3 months) (Figure 4).

\section{Discussion}

AML is a relatively not a common disease with high heterogeneity in terms of morphology, immunophenotype, cytogenetics and molecular abnormalities [8]. In the current study all patients were diagnosed by clinical picture, blood and bone marrow examination and immunophenotyping. Most of them were unable to pay for cytogenetic or molecular studies so that the researchers performed the cytogenetic studies in order to stratify them according to the cytogenetic risk groups. 


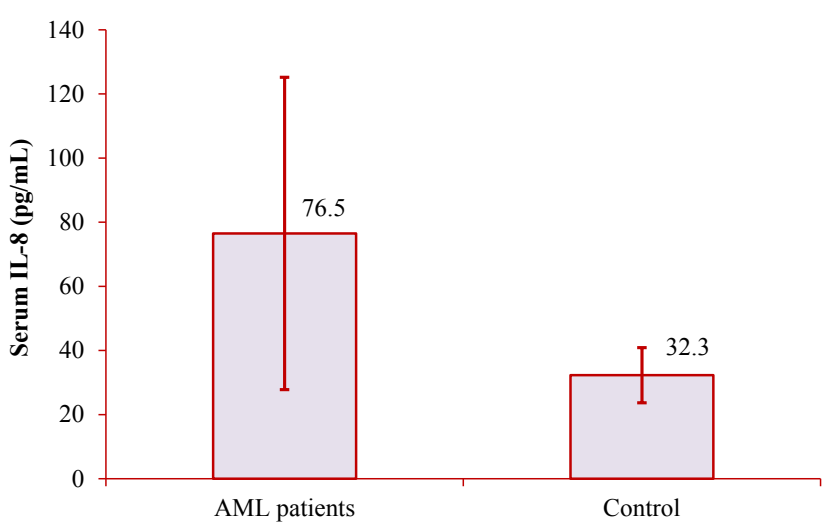

Figure 1: The mean IL-8 in the studied AML patients and the control group.

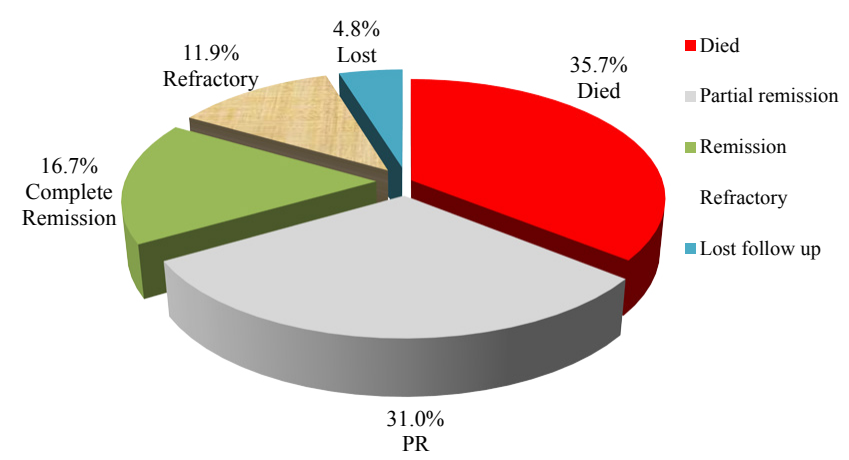

Figure 2: Outcome of the studied AML patients after 36 months of follow-up.
Acute myeloid leukemia in this study was diagnosed more among male patients. Similar to this finding was reported previously in the study of Padilha et al. [11], in Brazil where slight predominance of male than female among Caucasian AML patients. Similarly, Harrison et al. [12] reported higher male over female frequency among patients in the United Kingdom.

Age of AML patients is a recognized prognostic factor, with poorer survival for older adults than children [13]. The age of the studied patients was ranging from 19 to 64 years (median: 48 years). Similar age was reported in the clinical trial reported by Stone et al. [14] 48 years.

In this study, older patients ( $\geq 65$ years) were excluded to rule out the effect of age as a confounding factor in the elevation of IL-8. AML is common among patients younger than 65 years of age. In the study of Padilha et al. [11], they reported that the majority of their AML patients $(81.6 \%)$ were younger than 60 years of age.

The common FAB type in this study was M4 followed by M2, M3 and then M5. This is coinciding with the findings of Kakepoto et al. [15] in 2002 where they reported the FAB frequency of their AML patients to be M4 followed by M2 then M3 and M5. Harani et al. [16] in Karachi among 116 AML Pakistani patients, reported the common FAB types as M4 followed by M2, M3 then M1. In the study of Webb et al. [13], among 698 AML patients, the common FAB type was M2 followed by M5, M4 then M1.

The peripheral blood finings for the studied patients with AML showed that they present with anemia, thrombocytopenia and leukocytosis. Anemia and thrombocytopenia are the consequence of bone marrow infiltration by leukemic myeloblasts. In the study of Sultan et al. [17], anemia was noted in $81.6 \%$ of AML patients and thrombocytopenia in $84 \%$ of them.

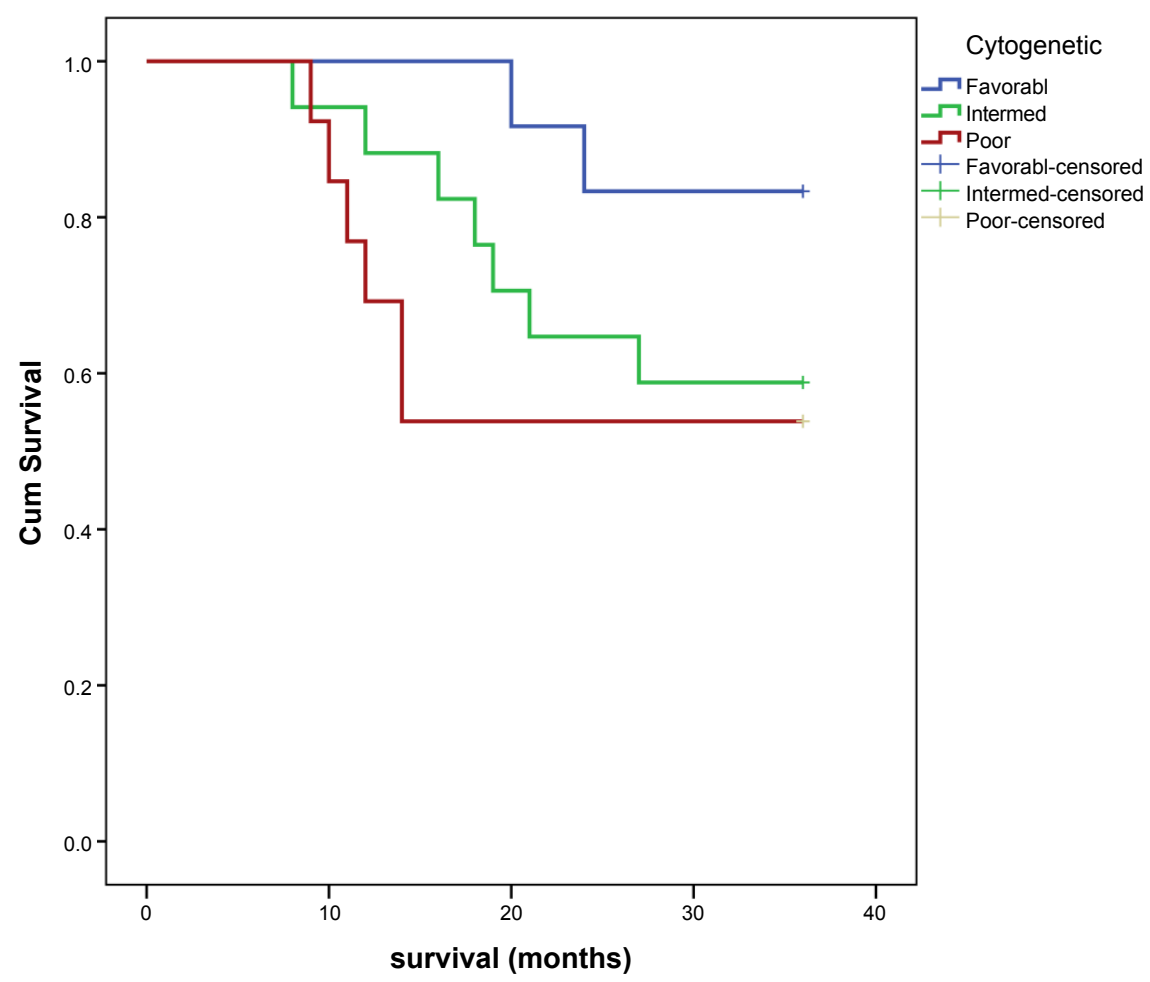

Figure 3: Survival analysis of the studied AML patients according to cytogenetic risk groups. 
Citation: Almorish MAW, Al-Kahiry WMA, Rabie MAF, Dammag EAM (2019) Interleukin-8 as a Surrogate Marker in Risk Stratification of Patients with Acute Myeloid Leukemia. J Blood Lymph 9: 240.

Page 4 of 6

\begin{tabular}{|c|c|c|c|c|c|c|}
\hline \multirow[t]{2}{*}{ Parameter } & & \multirow[t]{2}{*}{ No. } & \multicolumn{3}{|c|}{ Interleukin-8 (pg/mL) } & \multirow[t]{2}{*}{$p$-value } \\
\hline & & & Min-Max & Mean \pm s.d. & Median & \\
\hline \multirow[t]{2}{*}{ Sex } & Male & 25 & $73.7 \pm 44.5$ & $7.0-172$ & 75 & \multirow[t]{2}{*}{0.646} \\
\hline & Female & 17 & $81.0 \pm 56.1$ & $5.0-200$ & 73 & \\
\hline \multirow[t]{7}{*}{ FAB type } & AML-M1 & 3 & $82 \pm 51.9$ & $22.0-112.0$ & 112 & \multirow[t]{7}{*}{0.665} \\
\hline & AML-M2 & 10 & $82.8 \pm 50.3$ & $5.0-162.0$ & 76 & \\
\hline & AML-M3 & 8 & $54 \pm 36.4$ & $7.0-100.0$ & 50.5 & \\
\hline & AML-M4 & 12 & $70.1 \pm 60.6$ & $8.0-200.0$ & 49 & \\
\hline & AML-M5 & 6 & $89.3 \pm 41.9$ & $28.0-140.0$ & 92 & \\
\hline & AML-M6 & 2 & $121.5 \pm 24.8$ & $104.0-139.0$ & 121.5 & \\
\hline & AML-M7 & 1 & 88 & 88.0 & 88 & \\
\hline \multirow[t]{3}{*}{ Cytogenetic risk group } & Favorable & 12 & $54.3 \pm 35.2$ & $7.0-112$ & 40.5 & \multirow[t]{3}{*}{$0.006^{*}$} \\
\hline & Intermediate & 17 & $66.3 \pm 47.9$ & $5.0-172$ & 58.0 & \\
\hline & Poor & 13 & $110.4 \pm 45.0$ & $19.0-200$ & 106.0 & \\
\hline \multirow[t]{5}{*}{ Outcome } & Complete remission & 7 & $21.4 \pm 13.6$ & $5.0-42.0$ & 22 & \multirow[t]{5}{*}{$0.001^{*}$} \\
\hline & Partial remission & 13 & $66.2 \pm 37.9$ & $8.0-140.0$ & 60 & \\
\hline & Refractory & 5 & $84.2 \pm 42.0$ & $19.0-124.0$ & 98 & \\
\hline & Died & 15 & $108.8 \pm 48.4$ & $39.0-200.0$ & 106 & \\
\hline & Lost during follow up & 2 & $74.5 \pm 21.9$ & $59.0-90.0$ & 74.5 & \\
\hline
\end{tabular}

Table 4: The mean Interleukin-8 in relation to some parameters in the studied patients.

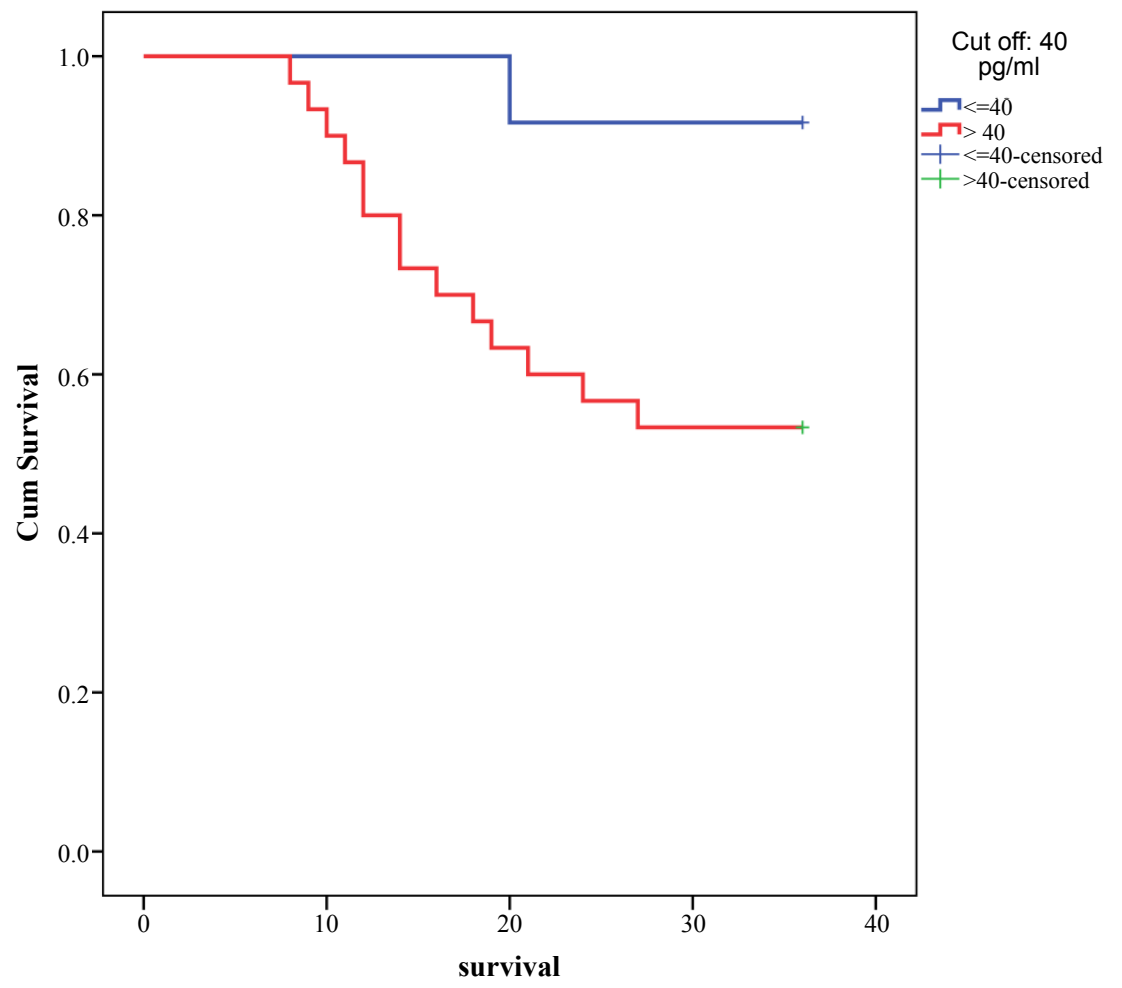

Figure 4: Survival analysis of the studied AML patients according to IL-8 level.

Untreated AML is a uniformly fatal disease. Although studied proved that patients can be supported for a certain period (median survival, 11-20 weeks) [18], ultimately, they may die of complications associated with failure of the bone marrow.

In this study, the follow-up time for the studied patients was 36 months. During this time one third of the patients died in spite of treatment and 2 patients were lost from follow-up. The case fatality rate can be estimated to be $37.5 \%$ ( 15 out of 40 followed cases).
Considerable efforts have been spent in identifying prognostic markers that might predict clinical outcomes in AML patients and several characteristics including older age, cytogenetics and performance status are commonly used as predictors of survival. In this study, because most of our patients cannot pay for cytogenetic or molecular studies, it was decided; after performing the cytogenetic studies, to select a simple ELISA test to be used as a surrogate marker in risk stratification of our AML patients.

Interleukin 8 was selected due to its potent proinflmmatory effect 
that induces trafficking of neutrophils across the vascular wall [8]. IL-8 belongs to a chemokine superfamily that includes neutrophil-activating peptide-2, platelet factor-4, growth-related cytokine, and interferon inducible protein-10, all of which are responsible for the directional migration of various cells [19]. In this study, serum IL-8 was found higher in patients with AML when compared to the normal control. The range was from 5 to $200 \mathrm{pg} / \mathrm{mL}$.

In the study of Bello et al. [20] they reported IL-8 among AML and ALL patients. They concluded that IL- 8 concentrations were significantly higher in AML patients when compared with ALL patients and control group, suggesting that IL- 8 may serve as an important biomarker for serum-based detection of acute leukemia, especially AML

In previous studies among patients with melanomas, IL-8 levels were found to be correlated with the growth and metastatic potential of the malignant melanoma cells. When the malignant cells were exposed to interferon, IL-8 levels decreased and cancer cell proliferation was also decreased [21].

In this study, IL-8 was evaluated as an alternative prognostic marker at the time of diagnosis prior to the start of chemotherapy. The mean serum IL- 8 was related to different variables in the studied AML patients. The variable that showed significant relationship to IL-8 were the cytogenetic risk groups and the clinical outcome $(p<0.05)$.

In the study of Schönbohn et al. [22] they found IL-8 levels significantly higher in those patients who subsequently developed major infection and they concluded that IL-8 levels may identify high risk or low risk patients with sufficient specificity and sensitivity; they recommended further large-scale clinical trials.

CXCR2 is the receptor for IL-8. In the study of Schinke et al. [23], they purified stem cells from AML and MDS patients and they found overexpression of IL8-CXCR2. They concluded that CXCR2 expression is associated with worse clinical outcomes. This finding is running parallel to the present study which found higher IL- 8 to be associated with poor risk group and worse clinical outcomes (died patients and refractory patients).

Furthermore, the gene expression data for 200 AML samples in the Cancer Genome Atlas Research Network study revealed high CXCR2 expression to be an adverse prognostic factor in AML patients [24].

The survival analysis of the studied patients showed that poor risk cytogenetic patients had mean survival time lower than intermediate and favorable risk groups. When the cut off value of $40 \mathrm{pg} / \mathrm{mL}$ (obtained by ROC curve) was used to analyze survival of the studied patients, it was found that significant higher survival time was found in AML patients with IL- $8 \leq 40 \mathrm{pg} / \mathrm{mL}$. These findings suggest that higher IL-8 was related to worse clinical outcomes in AML patients.

This study is not ignoring the role of cytogenetic and molecular studies in prognosis of AML, where in low resources areas they are considered sophisticated studies. However, it is trying to find a simple, cheaper test that can be a surrogate to the cytogenetic risk stratification to fulfill the requirements for the managing physicians during evaluation of AML patients.

The cost of IL- 8 analysis by ELISA will be more beneficial when compared to the cost of cytogenetic and molecular studies by FISH and PCR. It will make a difference for the patients as well as for the managing physicians in low resources areas.

\section{Conclusion and Recommendation}

This study concluded that serum IL-8 concentration at presentation of AML patients is high. It could be used as a surrogate marker for risk stratification and recommends its measurement in low resources areas where sophisticated studies are not available.

\section{Compliance with Ethical Standards}

\section{Ethical approval}

All procedures performed in this study involved AML patients and the control group were in accordance with the ethical standards of the institutional and/or national research committee and with the 1964 Helsinki declaration and its later amendments or comparable ethical standards.

\section{Informed consent}

An informed written consent was obtained from all individual participants (patients and control) included in this study.

\section{Funding}

This study was fully funded by the authors only.

\section{Conflict of Interest}

All authors declare that they have no conflict of interest.

\section{References}

1. Caceres-Cortes JR (2013) Blastic leukaemias (AML): A biologist's view. Cell Biochem Biophys 66: 13-22.

2. Arber DA (2018) Acute myeloid leukemia. In: Hematopathology (3rdedn), A Volume in the Series: Foundations in Diagnostic Pathology, pp: 429-466.

3. Shenghui Z, Yixiang H, Jianbo W, Kang Y, Laixi B, et al. (2011) Elevated frequencies of $C D 4+C D 25+C D 127^{10}$ regulatory $T$ cells is associated to poor prognosis in patients with acute myeloid leukemia. Int J Cancer 129: 13731381.

4. Sanchez-Correa B, Gayoso I, Bergua JM, Casado JG, Morgado S, et al. (2012) Decreased expression of DNAM-1 on NK cells from acute myeloid leukemia patients. Immunol Cell Biol 90: 109-115.

5. Van Etten RA (2007) Aberrant cytokine signaling in leukemia. Oncogene 26: 6738-6749.

6. Tsimberidou AM, Estey E, Wen S, Pierce S, Kantarjian H, et al. (2008) The prognostic significance of cytokine levels in newly diagnosed acute myeloid leukemia and high-risk myelodysplastic syndromes. Cancer 113:1605-1613.

7. Kornblau SM, McCue D, Singh N, Chen W, Estrov Z, et al. (2010) Recurrent expression signatures of cytokines and chemokines are present and are independently prognostic in acute myelogenous leukemia and myelodysplasia. Blood 116: 4251-4261

8. Ekmekcioglu S, Kurzrock R, Grimm EA (2015) Hematopoietic Growth Factors and Cytokines. In: Mendelsohn J, Gray JW, Howley PM, Israel MA, Thompson CB (editors). The Molecular Basis of Cancer (4th edn), Philadelphia, Expert Consult, Elsevier Inc., pp: 789-808.

9. Montserrat $E$, Hillmen $P$ (2016) Cytogenetic and molecular risk groups in acute myeloid leukaemia. In: Hoffbrand AV, Higgs DR, Keeling DM, Mehta AB (Editors). Postgraduate Haematology, (7th edn), UK, Wiley Blackwell, p: 365.

10. Döhner H, Estey E, Grimwade D, Amadori S, Appelbaum FR, et al. (2017) Diagnosis and management of AML in adults: 2017 ELN recommendations from an international expert panel. Blood 129: 424-447.

11. Padilha SL, dos Santos Souza EJ, Matos MCC, Domino NR (2015) Acute myeloid leukemia: Survival analysis of patients at a university hospital of Paraná. Rev Brasil Hematol Hemoter 37: 21-27.

12. Harrison CJ, Hills RK, Moorman AV, Grimwade DJ, Hann I, et al. (2010) Cytogenetics of childhood acute myeloid leukemia: United Kingdom Medical Research Council Treatment trials AML 10 and 12. J Clin Oncol 28: 2674-2681. 
Citation: Almorish MAW, Al-Kahiry WMA, Rabie MAF, Dammag EAM (2019) Interleukin-8 as a Surrogate Marker in Risk Stratification of Patients with Acute Myeloid Leukemia. J Blood Lymph 9: 240.

13. Webb DK, Harrison G, Stevens RF, Gibson BG, Hann IM, et al. (2001) Relationships between age at diagnosis, clinical features, and outcome of therapy in children treated in the Medical Research Council AML 10 and 12 trials for acute myeloid leukemia. Blood 98: 1714-1720.

14. Stone RM, Mandrekar S, Sanford BL, Geyer S, Bloomfield CD, et al. (2015) The multi-kinase inhibitor midostaurin (M) prolongs survival compared with placebo $(P)$ in combination with daunorubicin (D)/cytarabine (C) induction (ind), highdose $\mathrm{C}$ consolidation (consol), and as maintenance (maint) therapy in newly diagnosed acute myeloid leukemia (AML) patients (pts) age 18-60 with FLT3 mutations (muts): an international prospective randomized (rand) P-controlled double-blind trial (CALGB 10603/RATIFY. Am Soc Hematol 126: 6.

15. Kakepoto G, Adil S, Khurshid M, Bumey I, Zaki S (2002) Long-term outcomes of acute myeloid leukemia in adults in Pakistan. J Pakistan Med Association 52: $482-486$.

16. Harani MS, Adil S, Shaikh MU, Kakepoto GN, Khurshid M (2005) Frequency of fab subtypes in acute myeloid leukemia patients at Aga Khan University Hospital Karachi. J Ayub Med College 17: 26-29.

17. Sultan S, Zaheer HA, Irfan SM, Ashar S (2016) Acute Myeloid Leukemia: Clinical Spectrum of 125 Patients. Asian Pac J Cancer Prev 17: 369-372.
18. Pulsoni A, Pagano L, Latagliata R, Casini M, Cerri R, et al. (2004) Survival of elderly patients with acute myeloid leukemia. Haematologica 89: 296-302.

19. Xie K (2001) Interleukin-8 and human cancer biology. Cytokine Growth Factor Rev 12: 375-391.

20. Bello HJ, Shah STA, Hussain S (2018) Systemic levels of Interleukin 8 and Hematological Measures in Acute Leukemia Patients. Transylvanian Rev XXVI: 7489-7494.

21. Bar-Eli M (1999) Role of interleukin-8 in tumor growth and metastasis of human melanoma. Pathobiology 67: 12-18.

22. Schönbohn H, Schuler M, Kolbe K, Peschel C, Huber C, et al. (1995) Plasma levels of IL-1, TNF alpha, IL-6, IL-8, G-CSF, and IL1-RA during febrile neutropenia: Results of a prospective study in patients undergoing chemotherapy for acute myelogenous leukemia. Ann Hematol 71: 161-168.

23. Schinke C, Giricz O, Li W, Shastri A, Gordon S, et al. (2015) IL8-CXCR2 pathway inhibition as a therapeutic strategy against MDS and AML stem cells. Blood 125: 3144-3152.

24. Ley TJ, Miller C, Ding L, Raphael BJ, Mungall AJ, et al. (2013) Genomic and epigenomic landscapes of adult de novo acute myeloid leukemia. N Engl J Med 368: 2059-2074. 